\title{
MULTICULTURALIDAD Y EDUCACIÓN SOCIOSEXUAL
}

\author{
Águeda GÓMEZ SUÁREZ \\ Universidad de Vigo (España) \\ agueda@uvigo.es
}

\section{MULTICULTURAL AND SOCIOSEXUAL EDUCATION}

Resumen: En este texto se muestran diversas formas de organización sociosexual de diversas sociedades, extraídas del trabajo de campo antropológico realizado por la autora desde el año 2004 hasta la actualidad, en relación a las tipologías propuestas por Anne Bolin, esto es: tradiciones dos espíritus, rituales de género cruzado, géneros hermafroditas, matrimonio entre mujeres y roles de géneros cruzados (transgéneros) -con el fin de mostrar la diversa pluralidad de modelos y sistemas sexo/género existentes en las sociedades contemporáneas, -que incluye modelos matricéntricos o sociedades con tercer género-, realidades que cuestionan el patrón hegemónico occidental binario, heteronormativo y antropocéntrico.

Abstract: In this paper they show diverse forms of organization sociosexual of diverse societies, extracted from the fieldwork anthropological realized by the authoress from the year 2004 up to the current importance, in relation to the typologies proposed by Anne Bolin, this is: traditions two spirits, rituals of crossed kind, hermaphrodite kinds, marriage between women and roles of crossed genders (transgender) -in order the model diverse plurality and systems show sex / gender existing in the contemporary societies- that it includes matricentral models or societies with third gender-, reality that they question the hegemonic western binary frame, heteronormative and anthropocentrically

Palabras clave: Sistemas sexo/género; Diversidad sexual; Antropología sexual Sex/gender systems; Sexual diversity; sexual anthropology 


\section{Introducción}

Si bien es cierto que pareciera que todos los seres humanos nos reproducimos biológicamente de igual forma y que los roles que adoptamos mujeres y hombres son similares en todo el planeta, las interpretaciones culturales que de los mismos hechos realizan las diferentes sociedades, ponen en cuestión esta afirmación sobre la universalidad de la sexualidad humana y las identidades de género.

Las categorías sexuales están imbricadas en el sistema sexo-género e involucran significados, formas de entender a la persona y sus acciones, así como distinciones sociales y relaciones de poder. En los últimos años la Antropología de Género se ha puesto el objetivo de indagar la variabilidad de las culturas a la luz de sus construcciones simbólicas y sociales acerca de lo "masculino" y lo "femenino" y de las relaciones que intervienen entre estos. Entre las interpretaciones de género más hegemónicas y conservadoras que se inspiran en el modelo binario y heteronormativo, que relacionan a la "mujer" con la naturaleza, lo doméstico, las funciones expresivas, el poder informal, la reproducción y el sentimiento ; y al "hombre" con la cultura, lo público, las funciones instrumentales, el poder formal, la producción y la razón, están emergiendo otras perspectivas más renovadoras, otros modelos o sistemas sexo/género ${ }^{l}$ extraoccidentales que comprenden civilizaciones que admiten "paradigmas de géneros múltiples" (existencia de más de dos géneros), que interpretan la fertilidad y fecundación desde un punto de vista homonormativo² (Herdt, 1999) o donde los roles de género difieren del patrón occidental ${ }^{3}$ (Cosentino, 2013).

Para la corriente constructivista, a la que nos adherimos, la sexualidad en concreto, no es entendida como un hecho dado, fijo o permanente, vinculado con los impulsos biológicos naturales, las anatomías o las relaciones coitales, sino una construcción histórica y sociocultural cambiante que varía de acuerdo con la época, región geográfica, grupo social, generaciones o etnias, y es producto de una red de prácticas discursivas y sexuales orientando la conducta, los deseos y las fantasías eróticas de los sujetos ${ }^{4}$.

Pierre Bourdieu, en su texto "La dominación masculina" (2000), analizó el orden, la estructura sexual y las estructuras cognitivas dominantes entre los bereberes de la Cabilia,

1 En su ensayo pionero de los Estudios de Género "The Traffic in Women: Notes on the "Political Economy" of Sex (1975), la antropóloga estadounidense Gayle Rubin define el sistema sexo/género como "el conjunto de los dispositivos a través de los cuales una sociedad transforma a la sexualidad biológica en producto de la actividad humana, y en los que estas necesidades sexuales transformadas están satisfechas " (Rubin, en Lamas, 2007).

2 En el libro "Guardians of the Flutes", el antropólogo Gilbert Herdt escribe una monografía inicial de lo que él denomina la "homosexualidad ritualizada" entre los sambia, una tribu de los altiplanos orientales de Papúa, Nueva Guinea. Para los sambia, el proceso de convertirse en hombres debe lograrse a través de la intervención ritualizada que se inicia a los siete daños del niño y termina cuando el joven tiene un hijo. Además de otras prácticas, el niño debe realizar felaciones diariamente a los hombres mayores de la tribu ,con el fin de crear una reserva de masculinidad. Los hombres mantienen estos ritos de ingestión en secreto; los hombres amenazan de muerte a los niños si revelan esta información a las mujeres (Herdt, 1981) .

3 Por ejemplo, entre los bosquimanos kung de Kalahari, los aborígenes murgin de Australia y los ilongots de Filipinas, la figura de "mujer" no se relaciona con la idea de "madre fértil" y"mujer madre" como en occidente (Moore,1999).

4 En este sentido, se podrían clasificar a los sistemas sexo/género en dos grupos: digitales y analógicos. Los sistemas de sexo/género digitales encuadran la realidad dentro de un modelo binario, organizándola en categorías mutuamente excluyentes (ej. hombre-mujer, heterosexual-homosexual), y son típicos, por ejemplo, del Occidente. Responden al principio aristotélico de no-contradicción. Los sistemas sexo/género analógicos, en cambio, siguen el fluir complejo de la realidad, sin buscar etiquetarlo en una polaridad rígida y resultan entonces más flexibles, considerando la existencia de una extrema variabilidad de 'identidades genéricas' y de orientaciones sexuales, también ambiguas e inestables. En otras palabras, se basan en el estatuto de la copresencia. (Gómez, 2009). 
con el fin de entender cuáles son los mecanismos responsables de las estructuras de la división sexual y social. También quiso conocer si estos mecanismos son similares o diferentes, en función de la historia, cultura y contexto de este grupo étnico estudiado. Efectivamente, para este autor, la perspectiva etnológica y antropológica resultó una de las estrategias heurísticas que posibilita subrayar el carácter arbitrario y contingente del orden sexual.

En este artículo, y siguiendo los pasos de Bourdieu, se pretende entender la dimensión propiamente simbólica del orden sexual dominante entre diferentes grupos étnicos: Bourdieu lo hace con los bereberes de la Cabilia, en Argelia; nosotros lo haremos a través del estudio de varios grupos étnicos y realidades sociales en México, principalmente.

Este texto es el producto de un largo trabajo de campo, realizado por la autora, sobre los sistemas sexo/género en diferentes grupos étnicos, entre los años 2005 y 2013 en diferentes lugares de México, tales como el Istmo de Tehuantepec, la sierra Tarahumara, el estado de Sonora y el estado de Veracruz, principalmente. También se extendió el trabajo de campo a grupos étnicos de países como Honduras, Guinea Bissau, la India y Panamá (Gómez, 2013, 2010, 2009, 2008), gracias al apoyo de entidades como la Agencia Española de Cooperación y Desarrollo del Ministerio de Asuntos Exteriores y Cooperación, los actuales Ministerio de Educación, Cultura y Deporte, el Ministerio de Economía y Competitividad del Gobierno de España, la entidad financiera Novacaixagalicia, la Universidad de Vigo y la Universidad de la Coruña ${ }^{5}$.

\section{Las tipologías de diversidad sexual en América Latina}

A través de diferentes coordenadas culturales, se comprende y conciben las "transgresiones de género" que se insertan al interior de la polaridad genérica masculino/femenino y que da cuenta de la extrema variabilidad humana de la construcción del género. En ese caso, el análisis se refiere a la realidad de América Latina, principalmente, aunque también se va a hacer referencia a las civilizaciones que existieron en América del Norte en el pasado.

Un ejemplo claro de la existencia de disidencias sexuales las encontramos la sociedad otomí o hñahñú de Capula, comunidad del estado de Hidalgo, en el Valle del Mezquite, donde se desarrollan prácticas de poligamia masculina (Cabral y Flores, 2006). Entre los chinantecos de San Lucas Ojitlán cerca de Tuxtepec, en la región del Papaloapan del estado de Oaxaca, en los años 70, tal y como lo relata el antropólogo Miguel Bartolomé, en Semana Santa, durante la representación de la "Última Cena" los doce apóstoles eran los homosexuales o dzá büa del pueblo, todos ellos personas muy respetadas (Bartolomé, 2007). Además, este antropólogo recogió el dato de que las personas hacían el amor la primera vez en el altar de la iglesia, con el fin de ser bendecidos y tener fertilidad. También, según la

\footnotetext{
$5 \mathrm{La}$ autora ha dirigido diversas investigaciones aprobadas en concurrencia competitiva de las que deriva el texto presentado en este artículo, estas son: "Creación del Centro de Estudios en Género, Sexualidad y Etnicidad", AECID, Ministerio de Asuntos Exteriores y de Cooperación del Gobierno de España, 2012 y 2011, "Culturas sexuales indígenas en México", AECID, Ministerio de Asuntos Exteriores del Gobierno de España, Programa José Castillejo, Ministerio de Ciencia y Tecnología del Gobierno de España, 2009; "Etnicidad e identidades sexuales analógicas: elaboración de materiales didácticos”. Ministerio de Educación y Ciencia. 2008;"¿Existen sociedades matriarcales? Aprendiendo de la igualdad de género entre dos grupos étnicos: los bijagós (Guinea Bissau) y los zapotecas (México), Ministerio de Educación y Ciencia. 2008-2009; "Educando para la igualdad desde la antropología sexual: zapotecas, bijagós y otros grupos étnicos", Xunta de Galicia, 2007; Reflexiones sobre la igualdad de género en diferentes grupos étnicos del mundo: elaboración de material didáctico. Cátedra Caixanova de Estudios Feministas- Universidad de Vigo, 2007; “¿Existen sociedades matriarcales? aprendiendo de la igualdad de género entre dos grupos étnicos: los bijagós (Guinea Bissau) y los zapotecas (México)”. Universidad de la Coruña, 2006-2007; “; "Mujer y movilización étnica en la comunidad matriarcal de Juchitán, Oaxaca, México", Cátedra Caixanova de Estudios Feministas-Universidad de Vigo, 2005; "Mujer y movilización étnica en la comunidad matriarcal de Juchitán, Oaxaca, México (sej2004-0411-e), Ministerio de Educación y Ciencia, 2005-2007.
} 
investigadora Patricia Ponce, cerca de la comunidad de Zongolica, en el estado de Veracruz, es tradición vestir a los niños como si fuesen niñas, con el fin de "despistar" a los espíritus malignos.

Desde otro punto de vista, otras concepciones de los sistemas sexo/género nos remiten a otras realidades tales como la comunidad indígena yaqui "Sarmiento", (Hermosillo, Sonora, -frente a la tradición patriarcal yaqui-, donde las mujeres la conforman y ostentan el poder ${ }^{6}$ (Gómez,2009).

Asimismo, en la sociedad mestiza mexicana se encuentran ciertas peculiaridades sexo/ genéricas significativas: en el norte de México, el sexo entre varones no significa que estos asumen una identidad homosexual; en el sur de México, la figura del mayate (hombre "activo" sexualmente que se relaciona íntimamente con un hombre afeminado), define al varón activo en la relación homoerótica. En ambos casos, estos hombres presumen de su hombría y que no se consideran homosexuales o bisexuales (Nuñez, 2007).

Ante esta amplia y diversa realidad de las costumbres y formas de organización sociosexual, se pretende intentar categorizar de alguna manera esta infinita variabilidad de formas de entender los diversos sistemas sexo-género contemporáneos en los pueblos de América Latina. Para poder establecer criterios de validez transcultural en torno a las identidades sexuales, se va a recurrir a la clasificación que la autora Anne Bolin realiza a partir del trabajo de Gilbert Herdt, en su libro "Formas trasculturales de homosexualidad y el concepto gay", la autora Anne Bolin (Nieto, 2003). Esta tipología intenta abarcar todas las formas de diversidad sexual existentes en diferentes culturas que las resume en cinco prototipos: tradiciones dos espíritus, rituales de género cruzado, géneros hermafroditas, matrimonio entre mujeres y roles de géneros cruzados (transgéneros).

A partir de esta propuesta, vamos a intentar analizar con más precisión la diversa realidad sexo/genérica en América Latina

\section{Tradiciones “dos espíritus” o tercer género}

Este modelo es descrito por Bolin (2003) como una posición reconocida culturalmente de género transformado (hombres que desean actuar como mujeres) y un estatus adicional que incluye vestir parcial o totalmente como el otro género), la especialización ocupacional y la adopción de conductas y portes asociados al otro género o de forma mixta. La identidad de género es anterior (niñez) y/o independiente de la conducta sexual, aunque en ciertos casos se elige una pareja del mismo sexo biológico.

En algunas de las civilizaciones americanas del pasado se cree que la "diversidad" fue significativa, tal y como recogen las crónicas coloniales de los siglos XV y XVII ${ }^{7}$. Patricia

6 Entre las mujeres kilwias o kolew, en la sierra de San Pedro Mártir, en Arroyo de León; y los cochmí o cochimí en Baja California, también el poder político es ejercido y controlado por las mujeres (Gómez, 2009).

7 Es difícil conocer cómo fue la sexualidad de la población prehispánica en América Latina, sin embargo, sí se puede concluir que las observaciones hecha por los cronistas coloniales y los patrones culturales actuales, apuntan a que existía una cultura sexual diversa y heterogénea, done la ambigüedad genérica y las prácticas homoeróticas eran frecuentes. En Centroamérica y el Caribe, los homosexuales eran considerados como mágicos y con poderes sobrenaturales, según recoge Gonzalo Fernández de Oviedo. Según fray Bartolomé de las Casas, entre los mexicas de México la orientación de los hijos nunca fue motivo de tormento, cualquier varón podía ser hija y así los padres "le vestían de mujer, le enseñaban artes y le buscaban marido". Fray Gregorio García informa de la existencia de prostíbulos masculinos entre los incas, también la crónica de Pachacuti Yamqui relata que en tiempos del Inca Yupanqui "habían sido criados varios muchachos para que atendieran sexualmente a los soldados de guerra". Gonzalo Fernández de Oviedo relata en las islas Caribes el cacique Goanacagari cubría de oro y joyas a sus amantes varones. La homosexualidad femenina era muy conocida entre los incas y en Brasil, tal y como relata Felipe Guamán Poma de Ayala y Antonio de Herrera y Tordesillas, respectivamente, las mujeres varoniles gozaban de muchos privilegios y podían participar en combates y decisiones. Agustín Zárate relata la existencia de una provincia exclusiva de mujeres que solo consentían hombres con fines reproductivos, y donde 
Alberts y Evelyn Blacwood (López, 2005) descubrieron que entre los indios Crow había chamanes varones que vestían de mujeres y se dedicaban a conceder favores sexuales a los guerreros. Algo similar se ha detectado en las culturas mohave, zuni, hopo, navajo, yuman, crow, yokut, papago, cheyene, winnwbago, omaha, ojibwa, cocopa, apache, miami, yorok y piegan de Norteamérica (Webster y Newton, en Miano, 2002:192) ${ }^{8}$. En efecto, entre los pima,- habitantes del sudeste de EEEUU con lengua de tipo uto-azteca-, se concebía la existencia de personas a las que denominan wi-kovat, cuya identidad no deriva de su genitalidad, sino de su conducta dicotómica, de la realización de actividades de ambos géneros y que poseían una apariencia pública dual.

En la actualidad existen terceros géneros tales como los omeguid entre los kunas de Panamá (Nieto, 2003), los nawikis entre los rarámuris de la Sierra Tarahumara mexicana (Gómez, 2010) o los muxes del Istmo de Tehuantepec (México).

Esta tercera categoría de género implica "mucho más que una simple preferencia erótica o un comportamiento sexual" (Grémaux, en Cosentino, 2013). Sin embargo, casi todos los antropólogos que hasta ahora se han enfrentado con esta temática han tratado etnocéntricamente de etiquetar al tercer género según la elección del objeto sexual (predominantemente refiriéndose al fenómeno como homosexualidad institucionalizada), una vez más sin empujarse más allá de sus propias categorías y sobrepasando los datos etnográficos o considerándolos como excepciones.

El tercer género, entonces, constituye un género separado, autónomo y reconocido socialmente. Se le llama "tercer" (en el significado de "otro" - puesto que en unas sociedades el numero de los géneros admitidos puede llegar hasta a siete ${ }^{9}$ - ) para subrayar con fuerza su ruptura con el modelo binario y con el dimorfismo biológico. La alteridad y la originalidad de esta tercera categoría, frente a las otras dos universalmente difundidas, se deducen de unos factores culturales que recorren en los contextos que admiten su presencia.

El elemento principal que identifica al tercer género en todas las culturas en las que está presente, es la especificidad funcional de su rol al interior de la estructura social, pues su aporte es fundamental para hacer las tareas tanto masculinas como femeninas, y también, trabajos reservados específicamente para ellos (deberes ceremoniales, trabajos artesanales, practicas chamánicas, etc) y mantener viva la tradición. Esta especificidad ocupacional ha sido indicada como elemento central para su reconocimiento social. Además, este rol bien definido se acompaña frecuentemente con un estatus de prestigio social y simbólico, determinado por un recurrente poder económico junto al aura sobrenatural que rodea el tercer género, percibido como extraordinario ${ }^{10}$. En efecto, el tercer género está a tal punto incorporado en la sociedad que son frecuentes los cuentos mitológicos que hacen remontar su origen como género a los albores del tiempo, contemporáneamente a la creación del hombre y de la mujer ${ }^{11}$, o que explican su valencia simbólica haciendo referencia a un cosmos primordial

los hijos varones se iban a vivir con sus padres. Francisco López cuenta de las invencibles amazonas del imperio incásico, que recibían los nombres de chamchak, kakcha, warkana o komí, que poseían una connotación lésbica (López, 2005).

8 Otros autores constatan que existen culturas, como los kurtachi del Pacífico, los hua de Papúa Nueva Guinea o los antiguos castrexos gallegos, donde existe una institución, la "cuvada" que reconoce el papel del hombre en el alumbramiento de los hijos, observando patrones de tabús dietéticos o de reclusión durante el periodo del parto y postparto de sus esposas. Entre los huas, el hombre llega incluso a simular la menstruación (Meigs, 1976; Paigey Paige, 1981; Collier y Rosaldo, 1981; Drumont, 1978, en Beltrán et al, 2001:44)

9 Los Ciukci siberianos, por ejemplo, tienen siete géneros: masculino, femenino, tres géneros ulteriores para los biológicamente varones y otros dos para las hembras biológicas (Cucchiari, en Cosentino, 20013).

10 Pedro Cieza de León entrega datos de un tipo de homosexualidad religiosa donde "cada templo o adoratorio principal tiene un hombre (...), los cuales andan vestidos como mujeres y con estos, casi por vía de santidad y religión, tienen su ayuntamiento carnal los señores y principales (Lopez, 2005)

11 Hablando del tercer género norteamericano, Roscoe cita el punto de vista nativo según el que "cuando el 
indiferenciado, también desde el punto de vista sexual. Estos mitos, como fundadores de la realidad, no hacen nada más que legitimar el orden social existente, y, en este caso, instituir culturalmente la presencia de los géneros múltiples. Un ejemplo de estas "sociodicea" (mito fundador) se pueden encontrar en el contenido y la forma de diferentes textos sagrados de pueblos o grupos étnicos diversos como son los mayas de Palenque, los mixtecos de Oaxaca, los toltecas y nahuas de México, y de los quichés de Guatemala ${ }^{12}$.

La entrada en el tercer género por parte de los sujetos interesados está anunciada, individualmente y públicamente, por la presencia de indicios socialmente reconocidos, como sueños que Whitehead (en Cosentino, 2013), por ejemplo, afirma que al interior de la "cultura de la visión" norteamericana los sueños son reveladores del destino personal que reserva a cada uno un hado caprichoso, distribuyendo con cierto grado de casualidad roles sociales y de género. Además, otros indicios que revelan la pertenencia de un sujeto al tercer género son la preferencia, exprimida desde la infancia, por actividades y juegos que no corresponden a su propio sexo social, o nacimientos particulares.

En unas culturas, la transición hacia este particular estatus de género se produce públicamente a través de específicos ritos de pasaje, y, como precisa Roscoe con referencia al caso mohave, se trata de "un pasaje [...] no de masculino a femenino, sino de chico a alyha, una transición tanto de género como de edad" (Roscoe, en Consentino,2013).

Además, en muchas sociedades el particular estatus de tercer género está evidenciado por la ropa y el aspecto exterior, aunque este elemento identitario sea mucho menos relevante con respecto a lo ocupacional (y la presencia no sistemática de vestuario especifico lo hace evidente). La mayoría de las personas pertenecientes al tercer género, anatómicamente de sexo masculino, adopta indumentos femeninos y busca también fenotípicamente hacerse más semejante a las mujeres. Sin embargo, estas metamorfosis non deben engañar y hace regresar el estudioso al paradigma binario de género.

Un ejemplo de tercer género se encuentra entre los rarámuris de la sierra tarahumara. La flexibilidad de las relaciones afectivas y sexuales también caracteriza a esta población. Hay familias polígamas y poliginia, algo aceptado socialmente, aunque siempre es más sancionada la mujer con dos hombres en un mismo hogar. (Gómez, 2009). Sobre la homosexualidad en el periodo prehispánico, no existen datos, salvo la existencia de los términos lingüísticos "reneke" (Perez, 2001), "ropeke" o "ropechi” (Vaca, en Gómez, 2009) (persona que le gusta tener sexo con otra persona de su mimo sexo, no importa si es hombre o mujer, se usa más para la homosexualidad femenina), "nawiki" ("cantar, el que canta", se usa para designar a los homosexuales hombres), rope, puchicachi, bizacachi, rekes, ) u "osexuales". Ambas figuras, los ropekes y nawikis se definen no solo por su preferencia sexual sino que hay un interés por ser como las mujeres ${ }^{13}$ (pendientes, pañoletas, collares, pintura de labios, etc) o como los hombres. También se considera que puede haber renekes y nawikis de "mes

pueblo de los espíritus hizo a los hombres y a las mujeres, creó también a las/los berdache" (Roscoe, en Cosentino, 2013).

12 Entre los mayas, se encuentran tres momentos de creación de los seres humanos y sus correspondientes destrucciones, según el Popol Vuh. Así, de esta manera, nacen los primeros cuatro hombres, que al recibir a sus respectivas mujeres dan inicio a los primeros linajes quichés. Algunos de los hijos como Iquí Balam no tuvieron descendencia. Resulta interesante el hecho de que haya uno de los primeros cuatro hombres creados por los dioses que no haya tenido esposa, y mucho menos, descendencia. Lo que podría referir a un "tercer género" o a un homosexual. También la crónica de Pachacuti Yamqui relata que en tiempos del Inca Yupanqui se habla de un creador andrógino, el dios Chuqui Chinchay "guarda de los hermafroditas e indios de dos naturas" o Viracocha, en la cúspide del orden cosmológico, quien se le sugiere una dualidad sexual (López, 2005). Ente los tarahumaras, antiguamente adoraban a un solo dios padre-madre, representado por el sol y la luna (Gómez,2009).

13 Dicen que les gusta cambiar de pareja, les gusta estar gordos, como el estereotipo de belleza raramuri de la mujer "mientras más gordas, más hermosas". Les gusta realizar las actividades que hacen las mujeres normalmente en la vida cotidiana (Gómez, 2009). 
a mes" Estos cambios se relacionan con el ciclo lunar, que también regula la menstruación de las mujeres. Dependiendo de cómo esté la luna, esas personas se pueden convertir en renekes un mes y al mes siguiente dejar de serlo y después ser nuevamente reneke. Solo entre los hombres, existe esta mutación reversible. Consideran que nacen así, pues desde niños ya observan que se comporta como un "nawiki" (Perez, 2001; Gómez, 2009). Los "nawikis" realizan trabajos asignados tradicionalmente tanto al mundo masculino como femenino, y en algunos casos se cambian el nombre para feminizarlo:"Ramón se pone Ramona" (Gómez, 2009). Algunas "nawikis" mujeres se suelen vestir como los hombres, y viven en pareja por largo tiempo.

Otro ejemplo se encuentra entre los zapotecas del Istmo de Tehuantepec donde se reconoce un tercer género: los muxes'. Los muxe's son parte natural y normal de la composición genérica de la sociedad, y son valorados por su papel económico y cultural (BennholdtThomsen, 1997, en Miano, 2002). Si analizamos las características que ostentan los individuos autoidentificados como muxé en cuanto a su identidad, estatus, rol y su orientación erótica-afectiva, se observa que lo que los distingue es su condición de género más que su práctica sexual homoerótica. Se definen como “(...) ni hombre ni mujer, sino todo lo contrario" o "(...) un alma femenina en cuerpo de varón”, no se despojan de su identidad masculina y asumen su identidad femenina, naturalizando su condición por "nacimiento" o por voluntad de dios, señalando el carácter presocial de su condición. Su rol consiste en " (...)saber cómo ser hombre y mujer a la vez y también ser mejor hombre y mejor mujer" (Miano, 2002). Existen muxes' que mantienen su identidad y aspecto masculino, tal y como tradicionalmente ha sucedido; otros, únicamente mantienen su aspecto viril, pero se maquillan como las mujeres (las "pintadas"); otros muxes' se identifican como "travestis" al vestirse de mujer ocasionalmente (Miano, 2002:154). Pero en las últimas décadas, algunos muxes' han optado por mantener una apariencia femenina diariamente: son las denominadas "vestidas": ropas femeninas, peinados, accesorios, modo de andar "femenino", gestos, voz, expresiones faciales, lenguaje, se colocan nombres femeninos, van al baño "de mujeres", etc. Todo lo exageran pues no son imitaciones realistas de mujeres sino parodias, “(...) están jugando a las mujeres" (Gómez, 2009). A nivel de roles sociales, el muxé suele dedicarse a la realización de tareas identificadas como "femeninas": bordado, lavado de ropa, adorno de fiestas, cerámica ( tamguyú), plisado de olanes, tocados de trenzas, estéticas, bordados, rezadoras, comerciantes, etc. Muchos de ellos consideran al "buen muxe" al que: "trabaja para ayudar a su familia y a la sociedad, no aquellos que no ven más allá y solo piensan en pintarse" (Gómez, 2009).

Resulta difícil relacionar las prácticas sexuales "objetivas" con las identidades sexuales en general, ya que cada contexto social define de un modo u otro las identidades sexuales, sin que la "praxis social" del individuo sea determinante. Por ejemplo, en Juchitán, la práctica homoerótica de los hombres que se relacionan sexualmente con muxes' (los denominados "mayates", "machines" o "chichifos") ${ }^{14}$, no determina que la identidad sexual de estos hombres pueda ser catalogada como homosexual, pues socialmente son calificados como heterosexuales. En cambio, el muxe' es considerado socialmente como homosexual, y su erotismo se desarrolla partiendo de que no sienten deseo sexual por mujeres ni por otros muxe' (las relaciones sexuales entre dos muxe's se describen como lesbianismo): “(...) nos da la calentura, porque somos hombres, pero sentimos como mujer” (Gómez, 2009), sino que su deseo de concreta en hombres "de verdad" viriles, machos o "cabrones" en su comportamiento, siendo los más valorado los hombres casados con hijos. Ellos asumen ser

14 Los "mayates" son los varones autopercibidos y percibidos socialmente como heterosexuales, con novia o esposa, pero tiene relaciones sexuales con otras personas del mismo sexo por placer o por interés. El "machín" es el heterosexual varonil, fuerte, dominante y agresivo. El "chichifo" es un joven todavía indefinido en sus preferencias sexuales que vive a costa de un homosexual de mayor edad (Miano, 2002:156). 
el receptor en el sexo, pese a que puede haber una inversión de "roles" durante la práctica sexual, aunque no se reconoce públicamente. Consideran positivas sus experiencias como cuerpos sexuales de los deseos de los hombres. La práctica sexual se concreta sobre todo en relaciones peneanas y en felaciones: “(...) dios es el que dispone y él pone calor en diferentes huecos, eso es todo"(Gómez, 2009).

\section{Sociedades matricéntricas}

Más allá de la tipología acuñada por Bolin, se ha introducido otro modelo de sociedad donde el sistema sexo/género difiere del dominante. Autores como Burton (en Beltrán, 2001) consideran que no es la división sexual del trabajo sino la "ideología cultural de género" quien determina si una sociedad es más o menos simétrica respecto a las relaciones de género (Sacks, 1979; Burton, 1985; en Beltrán et al, 2001:49) ${ }^{15}$.

Según diferentes estudios antropológicos, sí se han encontrado lugares donde la mujer gozó de ciertas cuotas de poder que favorecían la igualdad entre ambos sexos: es el caso de los inuit norteamericanos o entre algunos pueblos de la Amazonía americana, (Moore, 1991). ¿Y hoy, todavía existen sociedades donde domine la igualdad entre géneros y la mujer no sufra discriminación? En el presente prevalecen sociedades donde la relación de género es excepcionalmente horizontal., los machiguenga de Perú, los kunas de Panamá o los zapotecas del Istmo de Tehuantepec en México, son algunas de estas sociedades que no obedecen al patrón patriarcal, androcéntrico y heteronormativo, y en el que la mujer posee poder, estatus y prestigio social.

La antropóloga Peggy Reevers Sanday (1981), considera que toda sociedad elabora unas "pautas simbólicas" para guiar el comportamiento y hacerlo previsible, muchas veces derivado de antiguos conceptos de poder sagrado que se refleja en el orden secular. Esta autora analiza las formas de "entender el mundo" de cada sociedad), una especie de etnofilosofía en torno a la forma de entender su relación con otros seres humanos, (qué significa ser hombre y ser mujer) con el medio y con el más allá. Después de un pormenorizado trabajo etnográfico comparativo elabora una tipología para clasificar a las distintas sociedades: sociedades de orientación interna, donde las fuerzas de la naturaleza son sacralizadas y las mujeres los controlan y manipulan; y sociedades de orientación externa, donde el poder es exterior a la propia sociedad: caza, guerra, migraciones forzadas, hambrunas, escasez de recursos, etc, y por ello predomina el poder masculino.

Esta autora considera que las sociedades donde el medio natural es fértil, generoso y amable; donde existe una baja división del trabajo sexual; en el que el parentesco es de carácter matrilineal; la organización social se rige por lógicas cooperativas, igualitarias y pacíficas; además, tanto a sexualidad como la maternidad son muy valoradas -por ejemplo, es más importante ser madre que ser esposa-, el papel de la madre es central en la sociedad y la mujer es autónoma económicamente y que, además, poseen historias de la creación con un simbolismo de origen femenino, estamos ante sociedades donde la mujer posee un significativo dominio.

Uno de los casos más significativos existentes en la actualidad es el la sociedad zapoteca ubicada en el Istmo de Tehuantepec de México. La base de la estructura social entre los zapotecos es la familia matricéntrica, cuyo referente medular es la "madre". Ellas son principalmente las encargadas de la tradición en el día a día, en el ámbito de la cotidianeidad, las que realizan el mayor esfuerzo por "reproducir" los usos, tradiciones, ritos y fiestas populares (Gómez, 2008). La mujer es la que vende los productos de casa en casa, en el mercado

15 Efectivamente, Anette Weiner se refiere a las mujeres trobiand son muy valoradas por su maternidad y ellas poseen una autopercepción elevada de sí mismas. Por otro lado, Michelle Rosaldo observa que no es un universal la unidad "madre- hijo" de la que se deriva la reclusión de la mujer en el ámbito doméstico, pues no todas las unidades domésticas se construyen en torno a la madre biológica y a la prole. (Moore, 1991). 
o viajando al exterior y quien resuelve la economía familiar. Generalmente, el hombre que lleva dinero a su casa y se lo entrega en su totalidad a su esposa. Si es agricultor o pescador lleva el producto de su trabajo y la mujer se encarga de su elaboración y venta. El prestigio social se establece a partir de ciertas generosas acciones, pues el estatus es mayor en las personas que "más dan”, no en las que "más tienen” (Gómez, 2008).

También entre el pueblo kuna del Archipiélago de Kuna Yala en Panamá, habitado por 80.000 personas de la etnia kuna, las mujeres son las que heredan las tierras de su familia y se ocupan de mantener, organizar y proteger a todos sus miembros. Además son la cabeza de familia: “...ellas, las madres, son como la tierra: nos protegen, nos cuidan conservan el pueblo y sus tradiciones" (De Pablo; Zurita, 2013). Los kuna poseen una sociedad matrilocal y, en algún caso, matrilineal, es decir donde la línea de sucesión pasa a través de la mujer. Un joven, después del matrimonio, debe vivir en la casa de su suegra y trabajar varios años con ellos, con el fin de que aprenda el oficio de su suegro. El divorcio no es común, cuando ocurre, es el marido el que debe abandonar el hogar. Existe una división tradicional del trabajo dentro de las familias: el hombre reúne cocos, cultiva los alimentos, proporciona leña, realiza reparaciones a la casa, hace la ropa suya y la de sus hijos, teje cestas y talla utensilios de madera. La mujer prepara los alimentos, recoge el agua de los ríos, descarga los barcos, cose prendas femeninas, lava la ropa y limpia la casa (Bartolomé, Barabás, 2004).

Políticamente nen el Congreso Kunanes las tmdf hace si no posee el respaldfo de las mujeres.ueblo ysus tradiciones"bajo con la exposicies y de, las decisiones las toman ambos sexos en el Congreso Kuna, pese a que existen más representantes políticos masculinos que femeninos, nada se hace si no posee el respaldo de las mujeres.

La tradición es conservada y recogida en los diseños de las molas - que son tejidos elaborados con varias telas de colores por las mujeres, y que tratan sobre temáticas,- junto con motivos florales y naturales del entorno-, vinculadas a estos eventos también están documentados en su Molas (Bartolomé, Barabás, 2004).

\section{Los rituales de género cruzado}

Esta tercera tipología acuñada por Bolin se refiere a la adopción del porte y gestualidad del otro género únicamente en contextos ritualizados concretos y no permanentes. Los travestidos, en ocasiones ceremoniales, rituales de reversión, -tales como los encontrados en las ceremonias funerarias rarámuris, o la covada, un ritual masculino vinculado al ciclo reproductivo femenino y muy presente en diversas culturas (Bolin, en Nieto, 2003)

Entre el pueblo rarámuri de la sierra Tarahumara, en el norte de México, durante las celebraciones de muertos, conocidas como "chuwíbaris" se permite que uno de los parientes del sexo opuesto al de la" o "el" difunto en cuestión, actúe asumiendo el papel de muerto o muerta, pero cargado de bromas de alto contenido sexual. El espíritu del difunto "posee" a este familiar político del sexo opuesto, y a través de él, se "despide" de su viudo o viuda, mediante muestras de cariño, gestos y cometarios de alto contenido sexual, por eso, los niños de la familia no suelen estar presentes. Esta última "despedida" solo se hace con la pareja, y no con los padres o hijos del difunto o difunta (Gómez,2009). Si el que murió es hombre, necesita tres fiestas y si es mujer, cuatro celebraciones. En estas fiestas se bebe teswino, y ya borrachos todo puede suceder, por ejemplo que el que represente a la mujer muerta acabe siendo penetrado por el viudo. También puede ocurrir que la mujer que representa al difunto acabe jugando sexualmente con la viuda de este (Pérez, 2001).

\section{Géneros hermafroditas}

Esta tipología, tal y como la describe Bolin (en Nieto, 2003), se refiere a la condición congénita de ambigüedad de las estructuras genitales reproductivas de forma tal que el sexo del individuo no esta claramente definido de modo exclusivo como varón o como mujer. 
Entre los navajos, el estatus de hermafrodita esta muy valorado y además consideran que existen tres sexos entre ellos: hombre, mujer y nadle, y tres estatus de género: nadle verdadero, nadle falso hombre o nadle falso mujer (no hermafroditas) que realizan tareas de hombre o mujer, tiene relaciones con ambos pero nunca con otros nadle y donde la homosexualidad no se acepta.

En Santo Domingo existe el guevedoce, individuos genitalmente ambiguos, al igual que los kwolu-aatmwol de Sambia o los trnim-man del pueblo pidgin neomelanesio (Bolin, en Nieto, 2003).

\section{Conclusiones}

Este trabajo pretende ser una aproximación al conocimiento de otros órdenes sociosexuales diferentes al hegemónico, a fin de romper con los esquemas cognitivos etnocéntricos que encorsetan la realidad en estrechas perspectivas y cuya consecuencia resulta ser la propia distorsión de la misma. El conocimiento de los "otros" extraoccidentales extiende el horizonte de lo que una sociedad o una cultura considera posible o imposible, deseable o indeseable, transformando socialmente el orden sociopolítico hegemónico, que desde las realidades micro y macro conforma nuevas perspectivas de las identidades sexuales y genéricas y de los propios sistemas sexo/género.

En definitiva, este recorrido por la amplia pluralidad de realidades sociosexuales en América Latina, y especialmente, en México, confirma que, desde la perspectiva intercultural, se puede elaborar una nueva epistemología sobre el género y la sexualidad humana que proponga nuevas categorías analíticas para el análisis y la aprehensión de la realidad social actual, en toda su extensión.

En un mundo cada vez más globalizado y multiétnico, se hace necesario contar con herramientas comprensivas de una realidad social cada vez más diversa y múltiple. La educación intercultural es una oportunidad para poder visibilizar, de forma didáctica, un enfoque educativo de carácter inclusivo sobre la sexualidad humana y donde la diversidad es reconocida y actúa como un ingrediente indispensable y positivo para una educación integral y de calidad.

Los estudios empíricos como el aquí presente, permiten construir modelos y programas de "educación intercultural" que articulan nuevos marcos conceptuales que enlazan más los distintos campos y marcos políticos, académicos y pedagógicos.

Los elementos que sustentan esta propuesta pretenden dar relevancia y coordinar los escasos esfuerzos que, en el ámbito académico, se le ha dedicado al análisis e investigación de las culturas sexuales entre los grupos étnicos de América Latina. Sin duda, todo ello se ha gestado desde una perspectiva global que se apoya en que el conocimiento de otras realidades culturales implica la consideración y la admiración por las personas que conforman estos pueblos minoritarios que nos proponen otras formas de interpretar el afecto, el género y la sexualidad, a modo de escuelas de etnofilosofías complejas y precisas. El análisis de estas realidades étnicas representa la posibilidad de crear puentes de comprensión e intercambio teórico, a partir del reconocimiento de una "epistemología del sur" en temas de género y sexualidad para trazar alianzas y estrategias múltiples para institucionalizar la perspectiva de género en el campo social y educativo.

\section{Bibliografía}

Amorós, Celia (2007): La gran diferencia y sus pequeñas consecuecias... para la lucha de las mujeres. Cátedra. Madrid.

Bartolomé, Miguel (1997): Librar el camino. Relatos sobre antropología y alteridad. Antropofagia. Buenos Aires. 
Bartolomé, Miguel Angel; Barabás, Alicia (2004): "Recursos culturales y autonomía étnica. La democracia participativa de los Kuna de Panamá". http://alhim.revues.org/index351.html

Beltrán, Elena; et al (2001): Feminismos: debates teóricos contemporáneos. Alianza Editorial. Madrid.

Bennholdt-Thomsen, Veronika (1994): Juchitán, la ciudad de las mujeres. Instituto Oaxaqueño e las Culturas. Fondo Estatal para la Cultura y las Artes. México.

Bourdieu, Pierre (2000): La dominación masculina. Anagrama. Madrid.

Butler, Judith (2002): Cuerpos que importan. Sobre los límites materiales y discursivos del "sexo". Paidós, Barcelona.

Cabral, Javier; Flores, Angel (2006): Salud sexual y reproductiva en jóvenes indígenas de las principales etnias de México. IMSS. México DF.

Careaga, Gloria; Cruz, Salvador (coord) (2004): Sexualidades diversas: aproximaciones para su análisis. Miguel Angel Porrúa. PUEG. México DF.

Castells, Manuel (2008): Mujeres y hombres: una relación imposible. Alianza. Madrid.

Cosentino, Chiara (2013): "La irreducible originalidad del tercer género el caso zapoteco", en "Gómez, Águeda, (coord.) (2013): Nuevas miradas sobre el género, la sexualidad y la etnicidad. Andavira. España.

Covarrubias, Miguel (1946): El Sur de México, INI, México.

De Sahagún, Bernardino (1999): Historia General de las cosas de la Nueva España. "Colección sepan cuantos...". Editorial Porrúa. México, D.F., México

De Las Casas, Bartolomé de (1984): Brevísima relación de la destrucción de las índias. Cátedra, Madrid.

De Pablo, O.; Zurita, J. (2013): Ellas mandan en el paraíso, en Revista “Yo, Dona”, mayo 2013.

Fausto-Exterling, Anne (2006): Cuerpos sexuados. Melusina. Barcelona.

Fernández de Oviedo, Gonzalo (1959): Historia General y Natural de las Indias, en Pérez de Tudela y Bueso, Juan;(ed.). Biblioteca de Autores Españoles. Ed. original en Sevilla, 1535; Atlas. Madrid.

Foucault, Michel (2002): Historia de la sexualidad: la voluntad de saber. Madrid: Siglo XXI. 1976

Gerhards, Junger (1995): Framing dimensions and framing strategies: contrasting ideal-and realtype frames. Social science Information. London.

Goffman, Erving. (1974): Frame analysis. Cambrigde. Harvard University Press. EEUU.

Gómez, Águeda (coord.) (2013): Nuevas miradas sobre el género, la sexualidad y la etnicidad. Andavira. España.

Gómez, Águeda (2010): Culturas sexuales indígenas: México y otras realidades II, Andavira, España Gómez, Águeda (2009): Culturas sexuales indígenas: México y otras realidades I, Andavira, España. Gómez, Águeda (2008): Matriarcados, etnicidad y sistemas sexo/género analógicos y digitales: los bijagós (Guinea Bissau) y los zapotecas (México), Universidad de Vigo, España.

Harris, Olivia; Young, Kate (comps): Antropología y feminismo. Anagrama. Madrid.

Heritier, Francois (2002): Masculinolfemenino. El pensamiento de la diferencia. Ariel Antropología. Barcelona.

Herdt, G. H. (1981): Guardians of the Flutes: Idioms of Masculinity. New York: McGraw-Hill.

Herdt, G. H. (1999): Sambia Sexual Cultures: Essays from the Field. University of Chicago Press

Lamas, Marta (comp) (2007): El género: la construcción cultural de la diferencia sexual. FCE. México.

Laqueur, Thomas (1994): La construcción del sexo. Cuerpo y género desde los griegos hasta Freud. Cátedra. Madrid.

León-Portilla, Miguel (1959): Visión de los vencidos. Relaciones indígenas de la Conquista. Ediciones UNAM, México, D. F.

López, E. (2005): "El rostro oculto de los pueblos precolombinos". http://www.idahomophobia.org/ article.php3?id_article $=89$

Martín Casares. Aurelia (2007): Antropología del género: culturas, mitos y estereotipos. Cátedra. Madrid.

Martínez, Benito; Vaca, Jesús; Breugelmans, Server (2002): Reflexiones en el bosque. CONACULTA. PACMYC Chihuahua. Gobierno de Chihuahua. Instituto Chihuahuense de la Cultura. Chihuahua. 
Miano, Marinella (2003): Hombre, mujer y muxe en el Istmo de Tehuantepec. Plaza y Valdés, CONACULTA, INAH. México DF.

Montemayor, Carlos (1995): Los tarahumaras. Pueblo de estrellas y barrancas. Aldus. México DF.

Moore, Henrietta (1999): Antropología y feminismo. Cátedra. Madrid.

Nieto, Jose Antonio (2003): Antropología de la sexualidad y diversidad cultural. Talasa. Madrid.

Núñez Noriega, Guillermo (2007): Masculinidad e intimidad: identidad, sexualidad y sida. Miguel Angel Porrua. El Colegio de Sonora. Sonora.

Ortner, Serry (1979): “¿Es la mujer al hombre lo que la naturaleza es a la cultura?”, en Harris, O. y Young, K. (comps). Antropología y feminismo. Anagrama. Madrid.

Pérez Castro, Juan Carlos (2001): Los reneke o nawiki, en Cuicuilco "Homosexualidad, género y cultura en México", Vol 8, n²3, septiembre-diciembre.

Pérez Archibold, Juan (1997): “Autonomía Kuna y Estado Panameño” Autonomías Étnicas y Estados Nacionales, M.Bartolomé y A. Barabas (Eds.) INAH. Oaxaca, México.

Pintado Cortina, Ana Paula (2000): Tarahumaras: pueblos indígenas del México contemporáneo. CDI-PNUD.

Ponce, Patricia (2006): Sexualidades costeñas, un pueblo veracruzano entre el río y la mar. CIESAS: México DF.

Quezada, Noemí (1996): Sexualidad, amor y erotismo. México prehispánico y México colonial. UNAM. Plaza y Valdés. México.

Reeves Sanday, Peggy (1981): Poder femenino y dominio masculino. Sobre los orígenes de la desigualdad sexual. Editorial Mitre, Barcelona.

Ricard, Robert (1986): La conquista espiritual de México, FCE, México.

Roscoe, Will (2007): The Zuni Man-Woman. Albuquerque: University of New Mexico Press, EEUU. Rubin, Gayle (1996): "El tráfico de mujeres: notas sobre la "economía política del sexo", en Lamas, Marta (comp). La construcción cultural de la diferencia sexual. UNAM. México

Ruz, Mario Humberto (1998): La semilla del hombre. Fertilidad y sexualidad entre los mayas contemporáneos, "Varones, sexualidad y reproducción", Editora Susana Lerner. (pp. 193221), El Colegio de México. México.

Snow, Hunt y Benford (1993): Framing process and identity construction in collective action. Presented at the Annual Meetings of the Midwest Sociological Society. Chicago

Stephen, Lynn (2002): "Sexualities and genders in Zapotec Oaxaca", en Latin American perspectives, 123, 29, 2: 41-59. 